Pacific Journal of Mathematics

LOCAL IDEALS IN A TOPOLOGICAL ALGEBRA OF ENTIRE
FUNCTIONS CHARACTERIZED BY A NON-RADIAL RATE OF

JAMES JeROME METZGE 


\title{
LOCAL IDEALS IN A TOPOLOGICAL ALGEBRA OF ENTIRE FUNCTIONS CHARACTERIZED BY A NON-RADIAL RATE OF GROWTH
}

\author{
JAMES J. MetZger
}

\begin{abstract}
In this paper a class of locally convex algebras of entire functions is considered: For fixed $\rho>0, \sigma>0$, and $n$ a positive integer, let $E[\rho, \sigma ; n]$ denote the space of all entire functions $f$ in $n$ variables which satisfy $|f(x+i y)|=O\left\{\exp \left[A\left(\|x\|^{\rho}+\right.\right.\right.$ $\left.\left.\left.\|y\|^{\circ}\right)\right]\right\}$ for some $A>0$. Sufficient conditions are given in order that the local ideal generated by a family in $E[\rho, \sigma ; n]$ coincides with the closed ideal generated by the family.
\end{abstract}

For $z=x+i y=\left(x_{1}+i y_{1}, x_{2}+i y_{2}, \cdots, x_{n}+i y_{n}\right) \in C^{n}$, write $\|z\|^{2}=$ $\|x\|^{2}+\|y\|^{2}=\sum_{k=1}^{n}\left(x_{k}^{2}+y_{k}^{2}\right)$. For $f: C^{n} \rightarrow C$ and $A>0$, let $\|f\|_{A}=$ $\sup \left\{|f(z)| \exp \left[-A\left(\|x\|^{\rho}+\|y\|^{\sigma}\right)\right]: z \in C^{n}\right\}$. The space $E=E[\rho, \sigma ; n]$ is a locally convex algebra over $C$, with the natural inductive limit topology from the Banach spaces $\left\{f\right.$ entire: $\left.\|f\|_{A}<\infty\right\}, A>0$.

For $\mathscr{T}$ a family of functions in $E$, write $\mathscr{F}(\mathscr{T}), \mathscr{F}-(\mathscr{T})$, and $\mathscr{F}_{\text {loc }}(\mathscr{T})$, respectively, for the ideal, closed ideal, and local ideal in $E$ generated by $\mathscr{T}$. The local ideal $\mathscr{F}_{\text {loc }}(\mathscr{T})$ consists of all $H \in E$ such that in a neighborhood of each $z_{0} \in C^{n}, H$ has the form $H=\sum_{j=1}^{r} h_{j} F_{j}$ for some $F_{1}, F_{2}, \cdots, F_{r} \in \mathscr{T}$ and $h_{1}, h_{2}, \cdots, h_{r}$ analytic in a neighborhood of $z_{0}$. The ideal $\mathscr{J}_{10 \mathrm{c}}(\mathscr{T})$ is closed in $E$ and contains $\mathscr{T}$; hence $\mathscr{F}(\mathscr{T}) \leqq \mathscr{F}^{-}(\mathscr{T}) \subseteq \mathscr{J}_{10 \mathrm{c}}(\mathscr{T})$. The problem to be considered is: Under what conditions is $\mathscr{J}-(\mathscr{T})=\mathscr{I}_{1 \mathrm{oc}}(\mathscr{T})$ in the space $E=$ $E[\rho, \sigma ; n]$ ?

Problems of this type have been studied in various algebras $E$ by many authors, among them: L. Ehrenpreis [2, 3], L. Schwartz [14], H. Cartan [1], L. Hörmander [5, 6], B. A. Taylor [15], J. J. Kelleher and B. A. Taylor [7, 8, 9], J. Metzger [11], I. F. Krasičkov [10], P. K. Raševskii [13], and K. V. Rajeswara Rao [12].

Let $\mathscr{T} \leqq E=E[\rho, \sigma ; n]$. It is known (see B. A. Taylor [15]) that for $n=1$ and $\rho=\sigma \geqq 1, \mathscr{F}-(\mathscr{T})=\mathscr{F}_{1 \mathrm{oc}}(\mathscr{T})$ in $E$ for any $\mathscr{T}$. If $\rho=\sigma$ and $\mathscr{T}=\{F\}$, but $n$ is arbitrary, then $\mathscr{I}(F)=\mathscr{J}-(F)=$ $\mathscr{J}_{100}(F)$ (see L. Ehrenpreis [2]). In [11] this author proved that if $n=1$, and $\rho \geqq 1$ or $\sigma \geqq 1$, then $\mathscr{F}^{-}(F)=\mathscr{J}_{1 \mathrm{oc}}(F)$ for any $F \in E$; if in addition $\rho \neq \sigma$, there exists an $F \in E$ for which $\mathscr{J}(F) \neq \mathscr{J}^{-}(F)$. Concerning the more general case where $n$ is arbitrary, and $\rho$ and $\sigma$ do not necessarily agree: Ehrenpreis's Quotient Structure Theorem (see [3]) implies that if $\rho>1$ and $\sigma>1$, and if $\mathscr{T}=\left\{F_{1}, F_{2}, \cdots, F_{r}\right\}$ consists of polynomials, then $\mathscr{F}(\mathscr{T})=\mathscr{F}-(\mathscr{T})=\mathscr{\mathscr { I }}_{\text {loc }}(\mathscr{T})$ in $E$. Also, a result of Hörmander [5] implies that when $\rho \geqq 1$ and $\sigma \geqq 1$, 
a family $\mathscr{T}=\left\{F_{1}, F_{2}, \cdots, F_{r}\right\}$ in $E$ satisfies $\mathscr{F}(\mathscr{T})=E$ if and only if there exist $\varepsilon>0$ and $A>0$ such that

$$
\sum_{j=1}^{r}\left|F_{j}(z)\right| \geqq \varepsilon \exp \left[-A\left(\|x\|^{\rho}+\|y\|^{o}\right)\right]
$$

for all $z \in C^{n}$.

In this papar the following result is proved:

THEOREM 1. Let $n$ be a positive integer, $\rho>0, \sigma>0$, and $\tau=$ $\max (\rho, \sigma) \geqq 1 ;$ and let $\mathscr{T} \leqq E[\rho, \sigma ; n] . \quad$ If $\mathscr{F}(\mathscr{T})=\mathscr{J}_{\mathrm{loc}}(\mathscr{T})$ in $E[\tau, \tau ; n]$, then $\mathscr{J}^{-}(\mathscr{T})=\mathscr{J}_{\text {loc }}(\mathscr{T})$ in $E[\rho, \sigma ; n]$.

Since $\mathscr{J}(F)=\mathscr{I}_{\mathrm{loc}}(F)$ in $E[\tau, \tau ; n]$, a consequence of Theorem 1 is:

COROLlary. Let $n$ be a positive integer, $\rho>0, \sigma>0$, with $\max (\rho, \sigma) \geqq 1$. Then $\mathscr{F}^{-}(F)=\mathscr{F}_{\text {loc }}(F)$ in $E=E[\rho, \sigma ; n]$ for any $F \in E$.

This corollary generalizes to several variables the result proved by this author in [11] for the case of one variable.

Theorem 1 follows immediately from an approximation theorem which is proved in the next section. In the third section Theorem 1 is applied to several examples.

2. The main theorem. The approximation theorem stated below, Theorem 2, yields Theorem 1 as an immediate corollary. The proof of Theorem 2 is based on a technique of L. Hörmander given in [6], which in turn involves the solution of the $\bar{\partial}$ equation (see [4, Chapter IV]).

THEOREM 2. Let $\sigma \geqq 1$, and $H, F_{1}, F_{2}, \cdots, F_{r}, G_{1}, G_{2}, \cdots, G_{r}$ be entire functions in $n$ variables, with $H=\sum_{j=1}^{r} G_{j} F_{j}$ and

$$
\left|G_{j}(z)\right| \leqq C \exp \left(A\|z\|^{o}\right)
$$

for all $z \in C^{n}, j=1,2, \cdots, r$, where $A, C$ denote positive constants. Then there exist positive constants $B, K$, and $M$, and entire functions $g_{j, t}, 0<t<1, j=1,2, \cdots, r$, such that:

$$
\begin{aligned}
& \left|H(z)-\sum_{j=1}^{r} g_{j, t}(z) F_{j}(z)\right| \\
\leqq & t K\left(1+\|z\|^{2}\right)^{M}\left\{|H(z)|+\left[\sum_{j=1}^{r}\left|F_{j}(z)\right| \exp \left(B\|y\|^{\sigma}\right)\right]\right\}
\end{aligned}
$$

for all $z \in C^{n}, 0<t<1$, and 


$$
\left|g_{j, t}(z)\right| \leqq L(t)\left(1+\|z\|^{2}\right)^{M} \exp \left(B\|y\|^{\sigma}\right)
$$

for all $z \in \boldsymbol{C}^{n}, 0<t<1, j=1,2, \cdots, r$, where $L(t)>0$ may depend on $t$ but not on $z$.

The proof of Theorem 2 is facilitated by the following:

Lemma. Let $n$ and $N$ be positive integers, with $N$ even. There exist $\alpha>0$ and $\varepsilon>0$ such that: If $z \in C^{n}$ with $\alpha\|x\| \geqq\|y\|$, then $\operatorname{Re}\left(z^{v}\right) \geqq \varepsilon\|z\|^{N}$.

Here $z^{v}=\sum_{k=1}^{n}\left(x_{k}+i y_{k}\right)^{N}$.

Proof. Write $q=N / 2$; then

$$
\operatorname{Re}\left[\left(x_{k}+i y_{k}\right)^{N}\right]=x_{k}^{2 q}+\sum_{m=1}^{q} a_{m} x_{k}^{2(q-m)} y_{k}^{2 m}
$$

for all $x_{k}+i y_{k} \in C$, where $a_{1}, a_{2}, \cdots, a_{q}$ are integers depending only on $N$. Hence for $z \in C^{n}$,

$$
\begin{aligned}
\operatorname{Re}\left(z^{N}\right) & \geqq \sum_{k=1}^{n} x_{k}^{2 q}-\sum_{m=1}^{n}\left|a_{m}\right|\left(\sum_{k=1}^{n} x_{k}^{2(q-m)} y_{k}^{2 m}\right) \\
& \geqq 2^{-(n-1)(q-1)}\|x\|^{2 q}-\sum_{m=1}^{q}\left|a_{m}\right|\|x\|^{2(q-m)}\|y\|^{2 m} .
\end{aligned}
$$

The required condition is then satisfied with $\varepsilon=2^{-[(n-1)(q-1)]-(q-2)}$, and $0<\alpha<1$ sufficiently small that $\sum_{m=1}^{q}\left|a_{m}\right| \alpha^{2 m}<2^{-[(n-1)(q-1)]-1}$.

Proof of Theorem 2. Let $N$ be an even integer, $N>\sigma$. By the lemma there exist $\alpha=\alpha(n, N)>0$ and $\varepsilon=\varepsilon(n, N)>0$ such that $\alpha\|x\| \geqq\|y\|$ implies $\operatorname{Re}\left(z^{N}\right) \geqq \varepsilon\|z\|^{N}$. Set $S=\left\{z \in C^{n}: \alpha\|x\| \geqq\|y\|\right.$ and $\left.\operatorname{Re}\left(z^{N}\right) \geqq 1\right\}$. The bounds (1) imply that for some $B>0$ and $K_{1}>0$,

$$
\left|G_{j}(z)\right| \leqq K_{1} \exp \left(B\|y\|^{\sigma}\right)
$$

for all $z \in C^{n} \backslash S, j=1,2, \cdots, r$.

Let $\varphi: R \rightarrow R$ be a $C^{\infty}$ function such that

$$
\begin{aligned}
\varphi(u)=0 & \text { if } \quad u \leqq 0, \\
& =1 \text { if } \quad u \geqq 1,
\end{aligned}
$$

and $0 \leqq \varphi(u) \leqq 1$ if $0 \leqq u \leqq 1$. For $0<t<1$ and $z \in C^{n}$, set

$$
\omega_{t}(z)=\left[\varphi\left(\operatorname{Re}\left(z^{N}\right)\right)\right] \exp \left[-t\left(z^{N}\right)\right]+\left[1-\varphi\left(\operatorname{Re}\left(z^{N}\right)\right)\right] \text {. }
$$

Each $\omega_{t}$ is a $C^{\infty}$ function on $C^{n}$; and $\left|\omega_{t}(z)\right| \leqq 1$ for all $z \in C^{n}$, while 
$\left|\omega_{t}(z)\right| \leqq \exp \left(-\varepsilon\|z\|^{N}\right)$ for all $z \in S$. Together with (1) and (4), this implies that for some $K_{2}>0$,

$$
\left|\omega_{t}(z) G_{j}(z)\right| \leqq K_{2} \exp \left(B\|y\|^{o}\right)
$$

for all $z \in C^{n}, \quad 0<t<1, j=1,2, \cdots, r$. Since $\left|1-e^{\zeta}\right| \leqq|\zeta|$ if $\operatorname{Re} \zeta \leqq 0$, and since $\left|z^{N}\right| \leqq n\|z\|^{N}$, it follows that $\left|1-\omega_{t}(z)\right| \leqq$ $t n\|\boldsymbol{z}\|^{N}$ for all $z \in \boldsymbol{C}^{n}, 0<t<1$. Consequently,

$$
\left|H(z)-\sum_{j=1}^{r}\left(\omega_{t}(z) G_{j}(z)\right) F_{j}(z)\right| \leqq t n\|z\|^{N}|H(z)|
$$

for all $z \in C^{n}, 0<t<1$. Thus the functions $\omega_{t} G_{j}$ satisfy conditions of the form (2) and (3).

As is done by Hörmander, the functions $\omega_{t} G_{j}$ will now be altered to obtain the desired analytic functions $g_{j, t}$. First of all, $\bar{\partial} \omega_{t}=0$ if $\operatorname{Re}\left(z^{N}\right) \leqq 0$, and $\left\|\bar{\partial}\left[\varphi\left(\operatorname{Re}\left(z^{N}\right)\right)\right]\right\| \leqq K_{3}\|z\|^{N-1}$ everywhere on $C^{n}$; therefore, $\left\|\bar{\partial} \omega_{t}(z)\right\| \leqq \operatorname{tn} K_{3}\|z\|^{2 N-1}$ for all $z \in C^{n}, 0<t<1$. Also, $\bar{\partial}\left(\omega_{t} G_{j}\right)=$ $\left(\bar{\partial} \omega_{t}\right) G_{j}$; and $\bar{\partial} \omega_{t}=0$ on $S$. By (4) then, for $0<t<1$ and $j=1,2, \cdots, r$,

$$
\left\|\bar{\partial}\left(\omega_{t}(z) G_{j}(z)\right)\right\| \leqq t K_{4}\|z\|^{2 N-1} \exp \left(B\|y\|^{o}\right)
$$

for all $z \in \boldsymbol{C}^{n}$, and thus

$$
\int_{c^{n}}\left\|\bar{\partial}\left(\omega_{t}(z) G_{j}(z)\right)\right\|^{2} e^{-\psi(z)} d \lambda(z) \leqq t^{2} K_{5}
$$

where $\psi(z) \equiv 2 B\|y\|^{\sigma}+(2 N+n) \log \left(1+\|z\|^{2}\right)$, and $\lambda$ denotes Lebesgue measure.

By applying Theorem 4.4.2 of Hörmander [4], functions $\nu_{j, t}$ of class $C^{\infty}$ on $C^{n}$ may be chosen such that $\bar{\partial} \nu_{j, t}=\bar{\partial}\left(\omega_{t} G_{j}\right)$ and

$$
\int_{C^{n}}\left|\nu_{j, t}(z)\right|^{2} \exp \left[-\psi(z)-2 \log \left(1+\|z\|^{2}\right)\right] d \lambda(z) \leqq t^{2} K_{5}
$$

for $0<t<1, j=1,2, \cdots, r$. Together with (7), this implies (see Hörmander [6, p. 314]) that

$$
\left|\nu_{j, t}(z)\right| \leqq t K_{6}\left(1+\|z\|^{2}\right)^{M} \exp \left(B\|y\|^{o}\right)
$$

for all $z \in C^{n}, 0<t<1, j=1,2, \cdots, r$, where $M=N+1+(1 / 2) n$.

Each of the functions $g_{j, t}=\omega_{t} G_{j}-\nu_{j, t}$ is then entire. Further, (3) is satisfied because of (5) and (8). Lastly $H-\sum_{j=1}^{r} g_{j, t} F_{j}=$ $\left[H-\sum_{j=1}^{r}\left(\omega_{t} G_{j}\right) F_{j}\right]+\sum_{j=1}^{r} \nu_{j, t} F_{j}$, and thus (2) follows from (6) and (8).

3. Examples and applications. In this section several examples are given where $\mathscr{I}^{-}(\mathscr{T})=\mathscr{J}_{1 \mathrm{oc}}(\mathscr{T})$ in spaces of the form $E[\rho, \sigma ; n]$.

ExAMPle 1. Let $E=E[\rho, \sigma ; n]$, with $\tau=\max (\rho, \sigma) \geqq 1$, and let $F \in E$. The corollary to Theorem 1 implies that $\mathscr{J}^{-}(F)=\mathscr{F}_{\mathrm{loc}}(F)$ 
in $E$. Also, $\mathscr{J}(F)=\mathscr{J}^{-}(F)=\mathscr{J}_{\text {loc }}(F)$ in $E[\tau, \tau ; n]$. However, it need not be the case that $\mathscr{J}(F)=\mathscr{J}-(F)$ in $E$; indeed, if $\rho \neq \sigma$ then (see [11]) there exists an $F \in E$ for which $\mathscr{J}(F) \neq \mathscr{J}^{-}\left(F^{\prime}\right)$.

EXAMPLE 2. Let $n=1$, and $E=E[\rho, \sigma ; 1]$, with $\tau=\max (\rho, \sigma) \geqq 1$. Let $\mathscr{T} \cong E$ and suppose some $F_{0} \in E$ has only finitely many zeros. Then $\mathscr{J}-(\mathscr{T})=\mathscr{I}_{\text {loc }}(\mathscr{T})$ in $E$. To prove this, write $F_{0}=P H$ where $P$ is a polynomial and $H \in E$ has no zeros. There exists a polynomial $Q$ such that $\mathscr{J}_{10 \mathrm{co}}(\mathscr{T})$ in $E$ is $\{G \in E: G / Q$ is analytic $\}$. Set $P=P_{0} Q$, so that $F_{0}=P_{0} Q H \in \mathscr{T} \cong \mathscr{F}(\mathscr{T})$. The factors of $P_{0}$ can bo divided out (see Taylor [15]) to yield $Q H \in \mathscr{F}(\mathscr{T})$ in $E$. Since $1 / H \in E[\tau, \tau ; 1]$, it follows that $Q \in \mathscr{I}(\mathscr{T})$ in $E(\tau, \tau ; 1)$, which implies that $\mathscr{I}(\mathscr{T})=$ $\mathscr{F}_{10 \mathrm{c}}(\mathscr{T})$ in $E[\tau, \tau ; 1]$, Then by Theorem $1, \mathscr{J}-(\mathscr{T})=\mathscr{I}_{\mathrm{Ioc}}(\mathscr{T})$ in $E=E[\rho, \sigma ; 1]$.

Note that if $1 / H \in E$-e.g., if $\rho \geqq 1, \sigma \geqq 1$, and $F_{0}$ is an exponential polynomial $F_{0}(z) \equiv P(z) e^{a z}$-then $Q \in \mathscr{I}(\mathscr{T})$ in $E$ and thus $\mathscr{I}(\mathscr{T})=$ $\mathscr{J}-(\mathscr{T})=\mathscr{I}_{1 \mathrm{oc}}(\mathscr{T})$ trivially. On the other hand, if $1 / H \notin E$ then $\mathscr{J}(\mathscr{T})$ need not coincide with $\mathscr{J}-(\mathscr{T})$ in $E$-for instance, if $\rho=1$, $\sigma=2$, and $\mathscr{T}=\left\{e^{-\left(z^{2}\right)}, e^{i z}-1\right\}$.

EXAMPle 3. Let $1 \leqq \rho<\sigma$ and $E=E[\rho, \sigma ; 1]$. Choose $\gamma, \rho<$ $\gamma<\sigma$; let $\varepsilon_{m}=\exp \left(-\left(2^{m \gamma}\right)\right), a_{m}=2^{m}, b_{m}=2^{m}+\varepsilon_{m}, m=1,2, \cdots ;$ and let

$$
\begin{aligned}
& F_{1}(z)=\prod_{m=1}^{\infty}\left(1-\frac{z}{a_{m}}\right) \\
& F_{2}(z)=\prod_{m=1}^{\infty}\left(1-\frac{z}{b_{m}}\right)
\end{aligned}
$$

for all $z \in C$. Each $F_{j}$ is an entire function of order 0 and thus is in $E$. Clearly $\mathscr{I}_{1 \mathrm{oc}}\left(F_{1}, F_{2}\right)=E$. It is easily argued that for $\rho<\rho^{\prime}<\gamma$, $\left|F_{2}\left(2^{m}\right)\right|=O\left[\exp \left(-\left(2^{m \rho^{\prime}}\right)\right)\right]$ as $m \rightarrow \infty$. Consequently $1 \notin \mathscr{F}\left(F_{1}, F_{2}\right)$ in $E$. On the other hand, letting $\gamma<\sigma^{\prime}<\sigma$ and using standard estimates on infinite products yields:

$$
\begin{aligned}
& \left|F_{1}(z)\right| \geqq \delta \exp \left(-|z|^{\sigma^{\prime}}\right) \quad \text { if } \quad z \notin \bigcup_{m}\left\{z:\left|z-a_{m}\right|<\frac{1}{2} \varepsilon_{m}\right\}, \\
& \left|F_{2}(z)\right| \geqq \delta \exp \left(-|z|^{\sigma^{\prime}}\right) \text { if } \quad z \notin \bigcup_{m}\left\{z:\left|z-b_{m}\right|<\frac{1}{2} \varepsilon_{m}\right\},
\end{aligned}
$$

where $\delta>0$. Thus $\left|F_{1}(z)\right|+\left|F_{2}(z)\right| \geqq \delta \exp \left(-|z|^{\sigma^{\prime}}\right)$ for all $z \in C$. It then follows (Hörmander [5]) that $1 \in \mathscr{J}\left(F_{1}, F_{2}\right)$ in $E[\sigma, \sigma ; 1]$. Hence $\mathscr{J}\left(F_{1}, F_{2}\right)=\mathscr{J}^{-}\left(F_{1}, F_{2}\right)=\mathscr{I}_{1 \mathrm{oc}}\left(F_{1}, F_{2}\right)$ in $E[\sigma, \sigma ; 1]$, while $\mathscr{J}\left(F_{1}, F_{2}\right) \subsetneq$ $\mathscr{F}^{-}\left(F_{1}, F_{2}\right)=\mathscr{I}_{1 \mathrm{oc}}\left(F_{1}, F_{2}\right)$ in $E=F[\rho, \sigma ; 1]$. 


\section{REFERENCES}

1. H. Cartan, Idéaux et modules de fonctions analytiques de variables complexes, Bull. Soc. Math. France, 78 (1950), 29-64.

2. L. Ehrenpreis, Mean periodic functions. I, Amer. J. Math., 77 (1955), 293-328.

3. - Fourier analysis in several complex variables, Pure and Appl. Math., 17, Interscience, New York, 1970.

4. L. Hörmander, An Introduction to Complex Analysis in Several Variables, D. Van Nostrand, Princeton, N. J., 1966.

5. - Generators for some rings of analytic functions, Bull. Amer. Math. Soc., 73 (1967), 943-949.

6. Convolution equations in convex domains, Invent. Math., 4 (1968), 306-317. 7. J. J. Kelleher and B. A. Taylor, An application of the Corona theorem to some rings of entire functions, Bull. Amer. Math. Soc., 73 (1967), 246-249.

8. - Finitely generated ideals in rings of analytic functions, Math. Ann., 193 (1971), 225-237.

9. - Closed ideals in locally convex algebras of analytic functions, in preparation.

10. I. F. Krasičkov, Closed ideals in the locally convex algebra of entire functions with an arbitrary growth majorant, Sov. Math. Dokl., 7 (1966), 1324-1325.

11. J. Metzger, Principal local ideals in weighted spaces of entire functions, Trans. Amer. Math. Soc., 165 (1972), 149-158.

12. K. V. Rajeswara Rao, On a generalized Corona problem, J. d'Analyse Math., 18 (1967), 277-278.

13. P. K. Raševskii, Closed ideals in a countably normed algebra of analytic entire functions, Sov. Math. Dokl., 6 (1965), 717-719.

14. L. Schwartz, Théorie générale des fonctions moyenne-périodiques, Ann. of Math.,

(2) 48 (1947), 857-929.

15. B. A. Taylor, Some locally convex spaces of entire functions, Entire Functions and Related Parts of Analysis (Proc. Sympos. Pure Math., La Jolla, Calif., 1966), Amer. Math. Soc., Providence, R. I., 1968, pp. 431-467.

Received November 14, 1972 and in revised form July 20, 1973.

UNIVERSITY OF GEORGIA 


\section{PACIFIC JOURNAL OF MATHEMATICS}

\section{EDITORS}

RICHARD ARENS (Managing Editor)

University of California

Los Angeles, California 90024

R. A. BeAumont

University of Washington

Seattle, Washington 98105
J. DugundJI*

Department of Mathematics

University of Southern California

Los Angeles, California 90007

D. Gilbarg and J. Milgram

Stanford University

Stanford, California 94305

\section{ASSOCIATE EDITORS}

E. F. BECKENBACH

B. H. NEUMANN

F. WOLF

K. YoSHIDA

\section{SUPPORTING INSTITUTIONS}

UNIVERSITY OF BRITISH COLUMBIA
CALIFORNIA INSTITUTE OF TECHNOLOGY
UNIVERSITY OF CALIFORNIA
MONTANA STATE UNIVERSITY
UNIVERSITY OF NEVADA
NEW MEXICO STATE UNIVERSITY
OREGON STATE UNIVERSITY
UNIVERSITY OF OREGON
OSAKA UNIVERSITY

UNIVERSITY OF BRITISH COLUMBIA CALIFORNIA INSTITUTE OF TECHNOLOGY UNIVERSITY OF CALIFORNIA MONTANA STATE UNIVERSITY NEW MEXICO STATE UNIVERSITY UNIVERSITY OF OREGON OSAKA UNIVERSITY
UNIVERSITY OF SOUTHERN CALIFORNIA STANFORD UNIVERSITY UNIVERSITY OF TOKYO UNIVERSITY OF UTAH WASHINGTON STATE UNIVERSITY UNIVERSITY OF WASHINGTON AMERICAN MATHEMATICAL SOCIETY NAVAL WEAPONS CENTER

* C. R. DePrima California Institute of Technology, Pasadena, CA 91109, will replace J. Dugundji until August 1974. 


\section{Pacific Journal of Mathematics}

\section{Vol. 51, No. $1 \quad$ November, 1974}

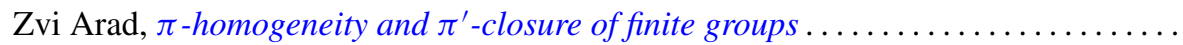

Ivan Baggs, A connected Hausdorff space which is not contained in a maximal

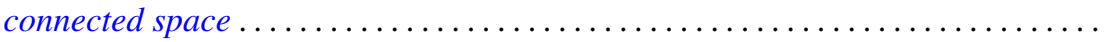

Eric Bedford, The Dirichlet problem for some overdetermined systems on the unit ball in $C^{n}$

R. H. Bing, Woodrow Wilson Bledsoe and R. Daniel Mauldin, Sets generated by

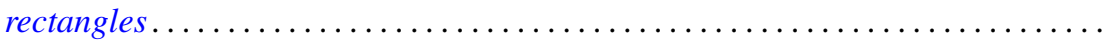

Carlo Cecchini and Alessandro Figà-Talamanca, Projections of uniqueness for

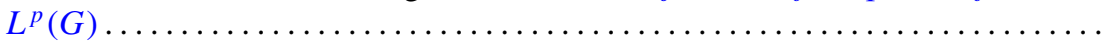

Gokulananda Das and Ram N. Mohapatra, The non absolute Nörlund summability of Fourier series .

Frank Rimi DeMeyer, On separable polynomials over a commutative ring ........ Richard Detmer, Sets which are tame in arcs in $E^{3} \ldots \ldots \ldots \ldots \ldots \ldots \ldots \ldots$

William Erb Dietrich, Ideals in convolution algebras on Abelian groups ..........

Bryce L. Elkins, A Galois theory for linear topological rings .................

William Alan Feldman, A characterization of the topology of compact convergence on $C(X)$.

Hillel Halkin Gershenson, A problem in compact Lie groups and framed cobordism

Samuel R. Gordon, Associators in simple algebras.

Marvin J. Greenberg, Strictly local solutions of Diophantine equations

Jon Craig Helton, Product integrals and inverses in normed rings . . . . . . . . . . . .

Domingo Antonio Herrero, Inner functions under uniform topology . . .

Jerry Alan Johnson, Lipschitz spaces .

Marvin Stanford Keener, Oscillatory solutions and multi-point boundary value

functions for certain nth-order linear ordinary differential equations.

John Cronan Kieffer, A simple proof of the Moy-Perez generalization of the

Shannon-McMillan theorem .......................

Joong Ho Kim, Power invariant rings

Gangaram S. Ladde and V. Lakshmikantham, On flow-invariant sets .

Roger T. Lewis, Oscillation and nonoscillation criteria for some self-adjoint even

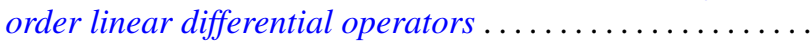

Jürg Thomas Marti, On the existence of support points of solid convex sets ..

John Rowlay Martin, Determining knot types from diagrams of knots . .

James Jerome Metzger, Local ideals in a topological algebra of entire functions

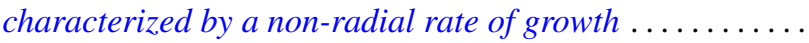

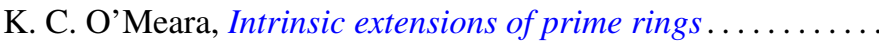

Stanley Poreda, A note on the continuity of best polynomial approximations ..

Robert John Sacker, Asymptotic approach to periodic orbits and local prolongations

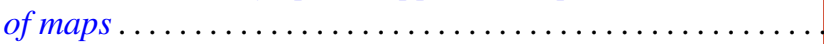

Eric Peter Smith, The Garabedian function of an arbitrary compact set . .

Arne Stray, Pointwise bounded approximation by functions satisfying a side condition

John St. Clair Werth, Jr., Maximal pure subgroups of torsion complete abelian

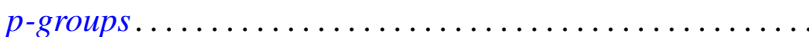

